BMJ Open

Diabetes

Research

\& Care

\title{
Medication usage, treatment intensification, and medical cost in patients with type 2 diabetes: a retrospective database study
}

\author{
Machaon Bonafede, ${ }^{1}$ Arthi Chandran, ${ }^{2}$ Stefan DiMario, ${ }^{2}$ Rita Saltiel-Berzin, ${ }^{3}$ \\ Drilon Saliu ${ }^{3}$
}

To cite: Bonafede $\mathrm{M}$, Chandran A, DiMario S, et al. Medication usage, treatment intensification, and medical cost in patients with type 2 diabetes: a retrospective database study. BMJ Open Diabetes Research and Care 2016:4:e000189. doi:10.1136/bmjdrc-2015000189

Received 22 December 2015 Revised 6 June 2016 Accepted 27 June 2016

\section{(1) CrossMark}

${ }^{1}$ Truven Health Analytics, Cambridge, Massachusetts, USA

${ }^{2}$ Health Economics and Outcomes Research, Becton Dickinson, Franklin Lakes, New Jersey, USA ${ }^{3}$ Medical Affairs, Becton Dickinson, Franklin Lakes, New Jersey, USA

Correspondence to Dr Machaon Bonafede; machaon.bonafede@ truvenhealth.com

\section{ABSTRACT}

Objective: The goal of this study was to describe medication usage patterns in patients with type 2 diabetes mellitus (T2DM) initiating treatment with noninsulin antidiabetic drugs (NIADs), basal insulin, or prandial/mixed insulin using real-world data.

Research design and methods: A retrospective analysis using the Truven Health MarketScan Research Databases was conducted to identify adults ( $\geq 18$ years) with T2DM from 2006 to 2012. Patients were categorized into four cohorts based on diabetes treatment. Cohort 1 ( $n=597664$ ) consisted of newly diagnosed patients who did not receive any treatment, cohort 2 ( $n=342511$ ) included NIAD initiators, cohort $3(n=99578)$ included basal insulin initiators, and cohort 4 ( $n=62876$ ) included prandial/mixed insulin initiators. Patients transitioned out of a cohort once they met the criteria for the next one.

Results: Patients in cohort 2 were younger (56.2 years, $S D \pm 12.1$ ) than patients in cohorts 1,3 , and 4 (58 years, $S D \pm 0.75$ ). Metformin was the most commonly prescribed drug in cohort 2 patients. Basal insulin usage decreased from $71 \%$ in year 1 to $47 \%$ in year 4 , in cohort 3 patients. Approximately one-third of these patients switched to $\mathrm{prandial} / \mathrm{mixed}$ insulin each year. In cohort 4 , the usage of prandial/mixed insulin decreased to $61 \%$ by year 4 . Use of basal insulin and NIAD remained common in this group. Mean glycosylated hemoglobin (HbA1c) values decreased by $\sim 1 \%$ for each of the treatment cohorts following treatment initiation and remained stable during followup. All-cause and diabetes-related medical costs were highest for patients in cohorts 3 and 4 .

Conclusions: Overall, our findings demonstrate that treatment intensification was low in all study cohorts despite elevated $\mathrm{HbA1c}$ levels during preindex and follow-up period.

\section{INTRODUCTION}

Type 2 diabetes mellitus (T2DM) is a common, chronic, progressive, and costly disease with an annual direct medical cost of $\$ 176$ billion and indirect cost of $\$ 69$ billion in the USA. ${ }^{1}$ A recent study reported that a

\section{Key messages}

- When glycosylated hemoglobin (HbA1c) is $\geq 9 \%$ and/or when patients remain uncontrolled despite maximally tolerated non-insulin antidiabetic medication, intensification of therapy with the addition of insulin is recommended.

- Patients starting basal or prandial/mixed insulin previously had extensive non-insulin medication despite prolonged elevated $\mathrm{HbA1C}$, suggesting a need for more aggressive treatment intensification.

- These findings may be particularly useful for health plans and providers planning interventions aimed at improving patient glycemic control and health outcomes. Future efforts should focus on facilitating treatment intensification in patients with uncontrolled type 2 diabetes.

person living with T2DM in the USA incurs $\sim \$ 85000$ in lifetime medical costs to treat the disease and its complications, suggesting that there may be opportunities for savings associated with more appropriate care. ${ }^{2}$ Maintaining glycemic control is the primary goal for patients with T2DM, which has been shown to reduce long-term diabetes-related complications, thereby reducing the clinical and economic burden. ${ }^{34}$

The American Diabetes Association (ADA)/European Association for the Study of Diabetes (EASD) guidelines recommend starting metformin at the time of diagnosis. ${ }^{5}$ Additional non-insulin antidiabetic medications, glucagon-like peptide-1 (GLP-1) receptor agonist, or insulin may be added if non-insulin monotherapy at the maximal tolerated dose does not achieve or maintain glycosylated hemoglobin (HbA1c) targets within 3 months. ${ }^{5}$ The intensification of diabetes therapies also depends on the individual patient's characteristics, including age, comorbidities, the risk of hypoglycemia, and the provider's and patient's preferences. ${ }^{6}$ 
Despite evidence in literature documenting the benefits of good glycemic control, particularly early in the disease trajectory, people with T2DM often do not reach recommended glycemic targets. ${ }^{3}$ Findings from previous studies indicate that insulin-naive and insulinexperienced patients may have mean HbA1c values above the recommended target levels, reflecting the existence of patients with poor glycemic control in routine clinical care ${ }^{7-9}$ Furthermore, evidence from a recent analysis suggests that the reported median time to treatment intensification with insulin is 7 years after the start of the last non-insulin antidiabetic drug (NIAD). Mean HbAlc values $>9 \%(75 \mathrm{mmol} / \mathrm{mol})$ have been reported at the time of insulin initiation, indicating periods of prolonged hyperglycemia which can equate to long-term microvascular and macrovascular damage. ${ }^{10}$ The delay in timely treatment intensification has been termed 'clinical inertia' and is gaining prominence in diabetes management. ${ }^{11}$ Failure to achieve optimal glycemic control is often associated with an increased risk of developing complications as well as increased healthcare usage and costs. ${ }^{12}$

As inadequate glycemic control may signal the need for treatment modification, it is important to gain an understanding of treatment progression and intensification patterns in patients with T2DM. The goal of this retrospective database analysis was to describe treatment intensification patterns in patients with T2DM initiating therapy with NIAD, basal insulin, or prandial/mixed insulin using real-world data in the USA. As a secondary goal, the study estimated the average direct medical cost associated with diabetes treatment in this patient population.

\section{RESEARCH DESIGN AND METHODS \\ Study design and data source}

A retrospective cohort analysis of patients with T2DM was conducted using the Truven Health MarketScan Research Databases, a large administrative claims database comprising commercially insured patients in the USA. The Truven Health MarketScan Commercial Claims and Encounters and Medicare Supplemental and Coordination of Benefits (COB) (Medicare) Databases contain medical and prescription data on 35 million employees and their dependents, while the Medicare Database contains data of individuals with Medicare supplemental insurance paid for by employers. Detailed cost, use, and outcomes data are available for both databases covering inpatient services, outpatient services, and prescription drug claims. As deidentified data were used in this retrospective database analysis, institutional review board (IRB) approval was not sought.

\section{Study population}

Adult patients ( $\geq 18$ years of age) who were diagnosed with T2DM (International Classification of Diseases,
Ninth Revision, Clinical Modification (ICD-9-CM) diagnosis codes of $250 . x 0$ or 250.x2) from 1 January 2006 to 31 December 2011 (study period), with at least 12 months of continuous enrollment during preindex and postindex period, were included in the study. Index date was defined as the date of the first antidiabetic prescription. Patients with a medical claim for type 1 diabetes (ICD-9-CM diagnosis codes 250.x1 or 250.x3) and gestational diabetes (ICD-9-CM diagnosis code 648.8x) were excluded from the analysis.

Based on the use of T2DM medications during the preindex and index period, patients were categorized into four study cohorts for the purpose of this analysis (table 1). Cohort 1 consisted of patients with T2DM who had not received any treatment in the year prior to or following diagnosis. In cohort 1, index date was defined as the date of T2DM diagnosis. Cohort 2 consisted of patients with T2DM who were newly initiated on NIAD and had not received any antidiabetic medications during the preindex period. Cohort 3 included patients with T2DM who were newly initiated on basal insulin but could have previously used other antidiabetic medication during the preindex period. Likewise, cohort 4 included patients who newly started prandial or mixed insulin but could have previously used other antidiabetic medications during the preindex period. Patients were followed for a minimum of 1 year after the index date up to a maximum of 4 years. Patients were transitioned out of a cohort once they met the criteria for the next cohort. Patients could qualify for more than one cohort depending on the timing of diabetes medication usage.

Demographic characteristics (age, gender, geographic region, and health plan type) were described for the different cohorts on the index date. Clinical variables measured in the preindex period included HbAlc values, macrovascular complications (ie, myocardial infarction, ischemic heart disease, peripheral vascular disease, cerebrovascular disease, and congestive heart failure), and microvascular complications (ie, diabetic neuropathy, diabetic nephropathy, renal disease, and diabetic retinopathy). The presence of other comorbid conditions commonly associated with T2DM, such as obesity, hypertension, hyperlipidemia, and non-alcoholic fatty liver disease, was also evaluated. The Deyo-Charlson comorbidity index score was calculated to measure the severity of comorbid conditions using all of the diagnoses on medical claims from the 12-month preindex period. ${ }^{13}$

\section{Direct medical cost}

Total annual direct medical costs and resources associated with emergency department visits, inpatient stays, outpatient visits, and endocrinologist visits were estimated for patients in all cohorts. Mean costs associated with diabetes-related prescriptions and supplies were also calculated for all study cohorts. Direct medical costs were measured for the follow-up period as the amount reimbursed by the healthcare plan and represent total 
Table 1 Baseline demographic and clinical characteristics of study cohorts

\begin{tabular}{|c|c|c|c|c|}
\hline $\begin{array}{l}\text { Demographic and clinical } \\
\text { characteristics }\end{array}$ & $\begin{array}{l}\text { Cohort } 1 \\
\text { No medication }\end{array}$ & $\begin{array}{l}\text { Cohort } 2 \\
\text { NIAD initiators }\end{array}$ & $\begin{array}{l}\text { Cohort } 3 \\
\text { Basal insulin } \\
\text { initiators }\end{array}$ & $\begin{array}{l}\text { Cohort } 4 \\
\text { Prandial/mixed } \\
\text { insulin initiators }\end{array}$ \\
\hline Number of patients & 597664 & 342511 & 99578 & 62876 \\
\hline Age (mean (SD) (years)) & $59.1(13.9)$ & $56.2(12.1)$ & $57.8(12.2)$ & $59.1(13.2)$ \\
\hline \multicolumn{5}{|l|}{ Gender (\%) } \\
\hline Male & 49.0 & 54.3 & 54.8 & 52.7 \\
\hline Female & 51.0 & 45.7 & 45.2 & 47.3 \\
\hline \multicolumn{5}{|l|}{ Geographic region (\%) } \\
\hline North-East & 16.5 & 12.6 & 11.0 & 10.5 \\
\hline North Central & 29.9 & 27.4 & 29.0 & 29.4 \\
\hline South & 36.2 & 42.1 & 39.7 & 40.7 \\
\hline West & 16.9 & 17.3 & 19.7 & 18.8 \\
\hline Unknown & 0.6 & 0.6 & 0.6 & 0.6 \\
\hline \multicolumn{5}{|l|}{ Insurance plan type (\%) } \\
\hline Comprehensive & 19.0 & 12.8 & 15.4 & 17.7 \\
\hline EPO & 0.9 & 1.0 & 0.9 & 0.8 \\
\hline $\mathrm{HMO}$ & 15.6 & 17.3 & 20.0 & 19.1 \\
\hline POS (includes plans w/o capitation) & 7.7 & 9.0 & 9.1 & 8.7 \\
\hline PPO & 50.0 & 51.7 & 47.2 & 46.6 \\
\hline Unknown/missing & 4.0 & 4.4 & 3.7 & 3.8 \\
\hline $\begin{array}{l}\text { Other (basic/major medical, CHDP, } \\
\text { HDHP) }\end{array}$ & 2.8 & 3.7 & 3.6 & 3.4 \\
\hline $\begin{array}{l}\text { Deyo-Charlson comorbidity index (mean } \\
\text { (SD)) }\end{array}$ & $1.8(1.5)$ & $1.6(1.4)$ & $2.3(1.9)$ & $2.5(2.1)$ \\
\hline \multicolumn{5}{|c|}{ Microvascular and macrovascular complications (\%) } \\
\hline Diabetic neuropathy & 6.7 & 7.4 & 14.8 & 16.8 \\
\hline Renal disease & 9.8 & 7.4 & 16.0 & 19.7 \\
\hline Ischemic heart disease & 16.3 & 12.9 & 20.2 & 23.4 \\
\hline Disorders of lipid metabolism & 42.3 & 40.9 & 40.1 & 38.7 \\
\hline Hypertension & 54.7 & 52.2 & 56.3 & 58.5 \\
\hline
\end{tabular}

CHDP, Child Health and Disability Prevention; EPO, exclusive provider organization; HDHP, high-deductible health plan; HMO, house in multiple occupation; NIAD, non-insulin antidiabetic drug; POS, point of service; PPO, preferred provider organization.

costs from the perspective of a large managed care organization. Patient copayments and deductibles were not included in the total direct medical costs calculations. Costs were expressed in year 2012 US dollars.

\section{Statistical analyses}

Continuous variables were reported using mean and SD. Categorical variables were summarized using percentages. Data used for this study were obtained from administrative health insurance claims database and did not include any individually identifiable data. All statistical analyses were performed using SAS software V.9.2 (SAS Institute, Cary, North Carolina, USA).

\section{RESULTS}

\section{Demographic and clinical characteristics}

A total of 597664 patients with T2DM in cohort 1, 342511 in cohort 2, 99578 in cohort 3 , and 62876 in cohort 4 met the study inclusion and exclusion criteria (table 1). Patients in cohort 2 were younger ( 56.2 years, $\mathrm{SD} \pm 12.1$ ) than patients in cohorts 1,3 , and 4 (average of 58 years, $\mathrm{SD} \pm 0.75)$. More than half of the patients in cohorts 2, 3, and 4 were males, while $51 \%$ of the initially untreated patients in cohort 1 were females (table 1). Hypertension, lipid disorders, ischemic heart disease, and renal disease were the more commonly occurring comorbid conditions in each cohort. As reported in table 2, average HbAlc value for cohort 1 remained consistent at $6.2 \%(44 \mathrm{mmol} / \mathrm{mol})$ over the follow-up period. For patients in cohort 2, mean HbAlC was highest in the preindex period $(8.0 \%(64 \mathrm{mmol} / \mathrm{mol}))$ but decreased at year 1 after initiation of non-insulin therapy $(7.1 \%(54 \mathrm{mmol} / \mathrm{mol}))$ and remained consistent over the follow-up period; likewise, the proportion of patients with $\mathrm{HbAl} 1 \mathrm{c}>7.0 \%(53 \mathrm{mmol} / \mathrm{mol})$ decreased from $62.2 \%$ preindex to $51.7 \%$ postindex. For patients in cohorts 3 and 4 , mean HbA1C values were highest during the preindex period $(9.2 \%(77 \mathrm{mmol} / \mathrm{mol})$ and $8.9 \%(74 \mathrm{mmol} / \mathrm{mol})$, respectively). The percentage of patients with $\mathrm{HbAlc}>7.0 \%(53 \mathrm{mmol} / \mathrm{mol})$ decreased from $89.7 \%$ and $83.8 \%$ preindex to $83.4 \%$ and $80.0 \%$ postindex for cohorts 3 and 4, respectively. Overall, HbAlc values decreased by $\sim 1 \%$ in the year following treatment initiation and remained stable during the study follow-up period. However, it was observed 
Table $2 \mathrm{HbA} 1 \mathrm{c}$ values for study cohorts from preindex to year 4

\begin{tabular}{|c|c|c|c|c|c|}
\hline Cohorts & Preindex & Year 1 & Year 2 & Year 3 & Year 4 \\
\hline Cohort $1(\%)$ & 6.4 & 6.2 & 6.2 & 6.2 & 6.2 \\
\hline$\%>7.0$ & 11.3 & 7.9 & 20.2 & 23.9 & 26.5 \\
\hline Cohort $2(\%)$ & 8.0 & 7.1 & 7.1 & 7.2 & 7.3 \\
\hline$\%>7.0$ & 59.1 & 49.7 & 41.8 & 45.0 & 47.7 \\
\hline Cohort $3(\%)$ & 9.2 & 8.1 & 8.1 & 8.1 & 8.2 \\
\hline$\%>7.0$ & 88.9 & 82.7 & 74.0 & 82.0 & 74.1 \\
\hline Cohort $4(\%)$ & 8.9 & 8.0 & 8.0 & 8.1 & 8.0 \\
\hline$\%>7.0$ & 82.6 & 78.8 & 70.3 & 69.4 & 73.0 \\
\hline
\end{tabular}

HbA1c, glycosylated hemoglobin.

that despite treatment with antidiabetic medications, average HbA1c values did not decrease below $7.0 \%$ (53 $\mathrm{mmol} / \mathrm{mol}$ ) during the study follow-up period for patients in cohorts $2-4$.

\section{Medication usage}

As the average $\mathrm{HbAlc}$ value of patients with T2DM in cohort 1 was $6.2 \%(44 \mathrm{mmol} / \mathrm{mol})$, treatment initiation for up to 4 years postdiagnosis was low with roughly $9 \%$, $15 \%$, and $19 \%$ receiving medications by years 2,3 , and 4, respectively. Patients initiating treatment in this cohort were mainly prescribed oral antidiabetic medications which included biguanides (metformin), sulfonylureas, dipeptidyl peptidase-4 (DPP-4) inhibitors, and GLP-1 agonists. The majority $(72 \%)$ of the patients in cohort 2 initiated treatment with metformin. From year 1 to year 4, however, its usage decreased from $77 \%$ to $54 \%$.Other commonly prescribed treatments for this cohort included sulfonylureas $(15 \%)$, combination products $(8 \%)$, thiazolidinediones $(6 \%)$, DPP-4 inhibitors
(3\%), and GLP-1 agonists (1\%). A gradual increase in the use of incretin agents, such as GLP-1 agonists (3-4\%) and DPP-4 inhibitors (7-10\%), was observed during the follow-up period. As expected, the overall transition from non-insulin medications to insulin therapy was low $(\sim 1 \% /$ year $)$ for patients in this group (table 3 ).

Patients in cohort 3 primarily initiated treatment with insulin glargine $(69 \%)$ followed by insulin detemir $(21 \%)$ and NPH human insulin isophane suspensions $(10 \%)$. However, there was a decrease in usage of basal insulin. For example, insulin glargine usage decreased from $71 \%$ in year 1 to $47 \%$ in year 4 . Treatment with non-insulin medications remained common during the preindex and follow-up period (table 3). Between 33\% and $38 \%$ of patients were transitioned to prandial/ mixed insulin each year following basal insulin initiation. For patients in cohort 4 , there was a decrease in usage of mealtime and mixed insulin from year 1 to year 4 . For example, usage of insulin as part in year 1, 37.5\%,

Table 3 Concomitant medication usage among NIAD initiators, basal insulin initiators, and prandial/mixed insulin initiators

\begin{tabular}{|c|c|c|c|c|c|}
\hline & Preindex & Year 1 & Year 2 & Year 3 & Year 4 \\
\hline \multicolumn{6}{|l|}{ NIAD initiators } \\
\hline Metformin (\%) & - & 77.0 & 58.4 & 55.4 & 53.6 \\
\hline DPP-4 inhibitors (\%) & - & 6.9 & 7.3 & 8.5 & 9.5 \\
\hline GLP-1 agonists (\%) & - & 2.9 & 3.0 & 3.3 & 3.7 \\
\hline Sulfonylureas (\%) & - & 23.7 & 21.1 & 23.1 & 25.2 \\
\hline TZDs (\%) & - & 9.5 & 7.7 & 8.2 & 8.9 \\
\hline Fixed-dose combinations (\%) & - & 11.5 & 10.2 & 10.8 & 11.3 \\
\hline \multicolumn{6}{|l|}{ Basal insulin initiators } \\
\hline Metformin (\%) & 55.4 & 52.1 & 48.7 & 47.5 & 46.2 \\
\hline DPP-4 inhibitors (\%) & 15.8 & 12.4 & 10.9 & 10.3 & 9.7 \\
\hline GLP-1 agonists (\%) & 12.0 & 8.6 & 8.8 & 8.9 & 8.7 \\
\hline Sulfonylureas (\%) & 52.1 & 41.4 & 35.1 & 33.8 & 32.6 \\
\hline TZDs (\%) & 29.6 & 18.8 & 15.0 & 14.2 & 13.5 \\
\hline Fixed-dose combinations (\%) & 17.5 & 13.7 & 12.0 & 11.2 & 10.4 \\
\hline \multicolumn{6}{|l|}{ Prandial/mixed insulin initiators } \\
\hline Metformin (\%) & 49.1 & 44.1 & 41.2 & 40.3 & 39.0 \\
\hline DPP-4 inhibitors (\%) & 11.7 & 8.1 & 7.7 & 7.6 & 7.5 \\
\hline GLP-1 agonists (\%) & 10.4 & 6.1 & 6.8 & 6.9 & 6.8 \\
\hline Sulfonylureas (\%) & 46.7 & 29.9 & 24.8 & 23.8 & 23.6 \\
\hline TZDs (\%) & 24.7 & 14.1 & 11.1 & 10.3 & 10.0 \\
\hline Fixed-dose combinations (\%) & 14.0 & 8.9 & 8.0 & 7.5 & 7.3 \\
\hline
\end{tabular}

DPP, dipeptidyl peptidase; GLP, glucagon-like peptide; NIAD, non-insulin antidiabetic drug; TZD, thiazolidinedione. 
Table 4 Resource usage for study cohorts from year 1 to year 4

\begin{tabular}{|c|c|c|c|c|c|c|c|c|}
\hline \multirow{2}{*}{$\begin{array}{l}\text { Cohorts } \\
\text { All cause }\end{array}$} & \multicolumn{2}{|c|}{$\begin{array}{l}\text { Inpatient } \\
\text { admissions (\%) }\end{array}$} & \multicolumn{2}{|c|}{$\begin{array}{l}\text { Outpatient } \\
\text { visits (\%) }\end{array}$} & \multicolumn{2}{|c|}{$\begin{array}{l}\text { Endocrinologist } \\
\text { visits (\%) }\end{array}$} & \multicolumn{2}{|c|}{$\begin{array}{l}\text { Emergency } \\
\text { department visits (\%) }\end{array}$} \\
\hline & Year 1 & $\begin{array}{l}\text { Follow-up } \\
\text { (average) }\end{array}$ & Year 1 & $\begin{array}{l}\text { Follow-up } \\
\text { (average) }\end{array}$ & Year 1 & $\begin{array}{l}\text { Follow-up } \\
\text { (average) }\end{array}$ & Year 1 & $\begin{array}{l}\text { Follow-up } \\
\text { (average) }\end{array}$ \\
\hline Cohort 1 & 16.9 & 12.2 & 99.9 & 96.1 & 3.6 & 2.6 & 1.1 & 0.6 \\
\hline Cohort 2 & 11.0 & 10.7 & 99.1 & 97.0 & 5.5 & 4.8 & 2.3 & 2.4 \\
\hline Cohort 3 & 18.8 & 16.3 & 99.3 & 97.8 & 15.7 & 13.5 & 4.1 & 4.7 \\
\hline Cohort 4 & 23.8 & 19.5 & 99.2 & 97.7 & 19.1 & 15.3 & 4.8 & 5.0 \\
\hline \multicolumn{9}{|c|}{ Diabetes related } \\
\hline Cohort 1 & 0.2 & 0.1 & 95.4 & 42.8 & 2.1 & 0.9 & 1.1 & 0.6 \\
\hline Cohort 2 & 0.3 & 0.2 & 94.0 & 84.6 & 4.7 & 3.9 & 2.3 & 2.4 \\
\hline Cohort 3 & 0.9 & 0.8 & 95.7 & 90.7 & 15.1 & 12.9 & 4.1 & 4.7 \\
\hline Cohort 4 & 1.2 & 1.1 & 94.4 & 89.4 & 18.4 & 14.6 & 4.8 & 5.0 \\
\hline
\end{tabular}

dropped to $20.3 \%$ at year 4 . Similarly, there was a $12 \%$ decrease in the number of patients who used insulin lispro from year 1 to year 4 . Furthermore, it was noted that $69 \%$ of patients in cohort 4 who were using basal insulin in year 1 decreased during follow-up to $54 \%$ at year 4 . The decrease and drop-off in medication use noted above is a significant finding of the study. Overall, the majority of patients in cohorts 3 and 4 were extensively treated with non-insulin medications prior to initiation of basal or prandial/mixed insulin, indicating that early adoption of treatment intensification with insulin was limited despite elevated HbA1c in both groups.

\section{Direct medical costs}

Health resource usage for all four study cohorts is reported in table 4, while mean direct 'all-cause' and 'diabetes-related' medical costs are reported in table 5 . Patients in cohorts 3 and 4 had higher endocrinologist visits and inpatient admissions than patients in cohort 2. This could be attributed to the fact that patients in cohorts 3 and 4 spent long periods of time in poor glycemic control before insulin initiation. Early treatment intensification may have reduced the number of inpatient admissions and endocrinologist visits in these cohorts. All-cause medical expenditure for patients in cohort 2 was $\$ 8591$ in the first year versus $\$ 15339$ and $\$ 20350$ for patients in cohorts 3 and 4, respectively. Mean all-cause medical expenditure increased across study cohorts but remained relatively stable within each cohort, over time. Similarly, diabetes-related mean total costs were lower for cohort 2 (\$1333) compared with cohort 3 (\$2276) and cohort 4 (\$2779). However, these costs remained relatively stable over time within each cohort after initially declining at the end of year 1 . As expected, diabetes-related mean pharmacy cost increased from cohort 2 to cohort 4 but remained relatively stable within cohorts. For patients in cohort 2, mean diabetes-related pharmacy expenditure remained stable over the follow-up period, starting at $\$ 314$ in the first year and averaging $\$ 272$ in years $2-4$.
Mean total pharmacy costs for patients in cohort 3 increased modestly from $\$ 2346$ in year 1 to $\$ 2710$ in year 4 . Similarly, for patients in cohort 4 , mean pharmacy costs increased modestly from $\$ 2484$ in year 1 to $\$ 2762$ in year 4 .

\section{DISCUSSION}

The importance of early glucose control and its impact on patient prognosis cannot be overemphasized. Failure to intensify treatment is a common barrier in optimizing diabetes care. ${ }^{14} 15$ Findings from our study demonstrate clinical inertia seen in the real-world setting. For example, patients in cohorts 3 and 4 received extensive therapy with NIAD despite having mean HbAlc levels during the preindex period of $9.2 \%(77 \mathrm{mmol} / \mathrm{mol})$ and $8.9 \%(74 \mathrm{mmol} / \mathrm{mol})$, respectively, for whom intensification with insulin therapy would be beneficial. It is likely that these patients endured prolonged periods of poor glycemic control which may, in the long term, negatively impact health outcomes and contribute to increased medical costs. Furthermore, the use of multiple NIADs was common and remained consistent over time among most patients receiving treatment with basal and prandial insulin. Instead of insulin intensification, there was a decrease in the use of basal and prandial insulin over the follow-up period for patients in cohorts 3 and 4.

The choice of second-line agents used to intensify treatment after metformin monotherapy included sulfonylureas, thiazolidinediones, GLP-1 agonists, and DPP-4 inhibitors. These trends are consistent with recently published data about the overall use of antidiabetic drugs. ${ }^{16}{ }^{17}$ While metformin is regarded as the first-line agent in the treatment of T2DM, there is no consensus supporting the use of one second-line agent over another. ${ }^{18} 19$ Consistent with previous studies, we found that while sulfonylureas continue to be the most common choice for second-line therapy, their use decreased over time, while the use of other agents such as GLP-1 agonists and DPP-4 inhibitors increased. ${ }^{20-22}$ We also noticed a decline in the use of thiazolidinediones which have 
Table 5 Direct medical costs for study cohorts from year 1 to year 4

\begin{tabular}{|c|c|c|c|c|c|c|}
\hline \multirow[b]{2}{*}{ Cohorts } & \multicolumn{2}{|c|}{$\begin{array}{l}\text { All-cause medical } \\
\text { expenditure (US\$) }\end{array}$} & \multicolumn{2}{|c|}{$\begin{array}{l}\text { Diabetes-related medical } \\
\text { expenditure (US\$) }\end{array}$} & \multicolumn{2}{|c|}{$\begin{array}{l}\text { Diabetes-related prescription } \\
\text { expenditure (US\$) }\end{array}$} \\
\hline & Year 1 & Follow-up (average) ${ }^{\star}$ & Year 1 & Follow-up (average) ${ }^{\star}$ & Year 1 & Follow-up (average) \\
\hline Cohort 1 & 11997 & 8780 & 934 & 360 & - & - \\
\hline Cohort 2 & 8591 & 8005 & 1333 & 1095 & 314 & 272 \\
\hline Cohort 3 & 15339 & 12391 & 2276 & 1937 & 2346 & 2591 \\
\hline Cohort 4 & 20350 & 14999 & 2779 & 2186 & 2484 & 2704 \\
\hline
\end{tabular}

${ }^{*}$ Follow-up costs were averaged from year 2 to year 4 for all study cohorts.

become progressively unpopular since the controversial reports published on rosiglitazone. ${ }^{23} 24$

Adherence is an important factor in diabetes treatment, especially when considering real-world insulin therapy. Non-adherence to insulin therapy is associated with worse glycemic control ${ }^{25}$ and increased risk of diabetes-related microvascular complications. ${ }^{26}$ Nonadherence to insulin therapy was found to be significantly and independently associated with two aspects of injection burden: having to plan daily activities around insulin injections and injections interfering with activities of daily life. ${ }^{27}$ Most patients and physicians delay starting insulin therapy for several reasons, all of which contribute to clinical inertia: fear of increased risk of hypoglycemia and weight gain, higher costs, the 'bad reputation' that insulin therapy is a sign of disease progression, fear of dependency on the medication, needle anxiety, and other beliefs. ${ }^{28}$ Fear of hypoglycemia is a concern in patients prescribed insulin with T2DM. Inappropriate or aggressive titration can lead to hypoglycemia and this is one reason patients may skip doses, omit insulin, or stop therapy altogether. ${ }^{29}$ End-stage renal disease (ESRD) is a relative contradiction for patients on insulin and often, dialysis patients will require every other day or every 2-day basal injections due to the protein not being filtered through the dialysis machine. ${ }^{31}$ Once on insulin therapy, many factors could have potentially impacted the significant decrease in insulin use observed in our study, including financial burden due to high cost of medications, polypharmacy, tolerance issues, inconvenience, and persistence issues among insulin users. Future efforts to effectively manage T2DM need to focus on developing and implementing strategies to overcome potential barriers to insulin therapy with support from healthcare providers including physicians, nurses, and pharmacists. This can include designing educational tools for patient selfmanagement as well as creating ongoing collaborative relationships between patients and allied health professionals that facilitate timely monitoring of clinical outcomes. These strategies should focus on decreasing the barrier to insulin initiation and include ways to have patients continue long-term insulin therapy once they have made the transition. Patient support and follow-up cannot be overlooked as they are crucial to successful diabetes management.
As reported in previous studies, inadequate glycemic control is associated with long-term adverse clinical and economic consequences. ${ }^{32}$ A German study reported that the total average cost of diabetes care for 6 months post insulin initiation rose from $€ 579$ to $€ 961$, which included the cost of blood glucose monitoring and specialist care in addition to insulin itself. ${ }^{33}$ These costs were greater in patients with higher HbAlc values and body mass index, highlighting the importance of good glycemic control using early treatment intensification and lifestyle modification strategies. Similarly, results from our study report that average all-cause and diabetes-related medical costs were higher for patients in cohorts 3 and 4 . These two cohorts included patients on insulin who were further along in the course of their disease. Some cost drivers within these groups include increased visits to endocrinologists, due to a more complex insulin regimen, as well as increased hospitalizations due to either disease progression or adverse effects of insulin, notably severe hypoglycemia. Timely initiation of insulin therapy in this group can be beneficial in maintaining optimal glycemic control and therefore assist in reducing long-term complications and costs associated with uncontrolled T2DM. ${ }^{34-36}$

The results of our study should be interpreted keeping in mind potential limitations that are inherent to claims data. These include absence of certain information in the databases which may be relevant to the treatment and management of T2DM such as body weight, body mass index, adherence to lifestyle modifications, and health behavior information. The definition of T2DM is limited to the occurrence of specific diagnosis codes in the database making it dependent on the accuracy of claims coding. Administrative claims data include paid claims only and cannot identify a member's use of sample medications or therapies for which the member paid solely out of pocket. Alternatively, a claim for a medication does not necessarily mean the member actually took the medication. Furthermore, there may be members who elect not to fill their prescriptions for a variety of reasons (eg, out-of-pocket cost of the medication, inability to return to the pharmacy). However, neither member nor physician behavior was evaluated in the present analysis. Future studies are warranted to further elucidate these factors. Similarly, free generic medications, specifically 
metformin, may not have been captured in this study, resulting in a potential underestimation. The study did not account for the impact of comorbid conditions and other risk factors on treatment patterns. When assessing treatment intensification, we were not able to evaluate how adherence, side effects, cost, or contraindications impacted results. Also, the study did not look into reasons or predictors of various treatment patterns that were observed. Our study provided a conservative estimate of direct medical costs associated with the treatment of patients with a diagnosis code of T2DM. Indirect costs, including costs associated with lost productivity, were not estimated. Results from this study apply to a population of commercially insured patients and their dependents, limiting generalizability to other patient populations. Last, as this was an observational study, no causal inferences can be made from these data.

In conclusion, our analysis provides an understanding of treatment intensification patterns observed in a realworld setting and supports findings from other studies that have demonstrated delays in escalating treatment intensity in patients with poor glycemic control despite recommendations set forth in the guidelines. These findings may be particularly useful for health plans and providers planning interventions aimed at improving glycemic control and health outcomes. Findings from other studies suggest that early insulization may be more cost-effective than prescribing multiple non-insulin therapies. However, there is a level of uncertainty as to when insulin should be initiated in patients exhibiting poor glycemic control in routine clinical practice and how to identify patients who are more likely to benefit from early insulization. A variety of patient-related factors such as adherence to treatment, occurrence of drug-related side effects, medication contraindication (eg, worsening of kidney function), and cost of medications along with provider-related factors have been found to delay initiation of early treatment intensification when warranted and therefore negatively impact clinical outcomes. ${ }^{11} \quad 15$ 37-39 Various approaches have been proposed to help overcome clinical inertia, such as implementing a patient-centered approach, promoting patient self-management, and providing education for physicians and patients with diabetes. ${ }^{39}$ Future efforts should be aimed at developing and assessing interventions which facilitate treatment intensification in patients with uncontrolled T2DM.

Acknowledgements The authors wish to thank Shalaka Marfatia of pharmEDGE for providing writing and editorial assistance.

Contributors In accordance with the guidelines from the International Committee of Medical Journal Editors, all authors have contributed significantly to the development of this manuscript. MB, AC, RS-B, and DS contributed to the design of the study. MB, AC, and SD interpreted the findings of the analysis. All authors contributed to the drafting and critical review of the manuscript. All authors have provided final approval to the manuscript.

Funding This work was funded by Becton Dickinson, Franklin Lakes, NJ, USA. All authors will be listed as guarantors.
Competing interests None declared.

Provenance and peer review Not commissioned; externally peer reviewed.

Data sharing statement No additional data are available.

Open Access This is an Open Access article distributed in accordance with the Creative Commons Attribution Non Commercial (CC BY-NC 4.0) license, which permits others to distribute, remix, adapt, build upon this work noncommercially, and license their derivative works on different terms, provided the original work is properly cited and the use is non-commercial. See: http:// creativecommons.org/licenses/by-nc/4.0/

\section{REFERENCES}

1. American Diabetes Association. Economic costs of diabetes in the U.S. in 2012. Diabetes Care 2013;36:1033-46.

2. Zhuo X, Zhang P, Hoerger TJ. Lifetime direct medical costs of treating type 2 diabetes and diabetic complications. Am J Prev Med 2013;45:253-61.

3. Holman RR, Paul SK, Bethel MA, et al. 10-year follow-up of intensive glucose control in type 2 diabetes. $N$ Engl $\mathrm{J} \mathrm{Med}$ 2008;359:1577-89.

4. Turnbull FM, Abraira C, Anderson RJ, et al. Intensive glucose control and macrovascular outcomes in type 2 diabetes. Diabetologia 2009;52:2288-98.

5. American Diabetes Association. Standards of medical care in diabetes-2015. Diabetes Care 2015;38(Suppl 1):S1-S93.

6. American Diabetes Association. Standards of medical care in diabetes-2014. Diabetes Care 2014;37(Suppl 1):S14-80.

7. Valensi P, Benroubi M, Borzi V, et al., IMPROVE Study Group Expert Panel. The IMPROVE study-a multinational, observational study in type 2 diabetes: baseline characteristics from eight national cohorts. Int J Clin Pract 2008;62:1809-19.

8. Sreenan S, Vikramäki A, Zhang K, et al. Switching from NPH insulin to once-daily insulin detemir in basal-bolus-treated patients with diabetes mellitus: data from the European cohort of the PREDICTIVE study. Int J Clin Pract 2008;62:1971-80.

9. Home P, Naggar NE, Khamseh M, et al. An observational non-interventional study of people with diabetes beginning or changed to insulin analogue therapy in non-Western countries: the A1chieve study. Diabetes Res Clin Pract 2011;94:352-63.

10. Calvert MJ, McManus RJ, Freemantle N. Management of type 2 diabetes with multiple oral hypoglycemic agents or insulin in primary care: retrospective cohort study. Br J Gen Pract 2007;57:455-60.

11. Khunti K, Wolden ML, Thorsted BL, et al. Clinical inertia in people with type 2 diabetes: a retrospective cohort study of more than 80,000 people. Diabetes Care 2013;36:3411-17.

12. Meneghini LF. Intensifying insulin therapy: what options are available to patients with type 2 diabetes? Am J Med 2013;126 (Suppl 1):S28-37.

13. Deyo RA, Cherkin DC, Ciol MA. Adapting a clinical comorbidity index for use with ICD-9 CM administrative databases. J Clin Epidemiol 1992;45:613-619.

14. Karter AJ, Moffet HH, Liu J, et al. Achieving good glycemic control: initiation of new antihyperglycemic therapies in patients with type 2 diabetes from the Kaiser Permanente Northern California Diabetes Registry. Am J Manag Care 2005;11:262-70.

15. Grant RW, Cagliero E, Dubey AK, et al. Clinical inertia in the management of type 2 diabetes metabolic risk factors. Diabet Med 2004;21:150-5.

16. Turner LW, Nartey D, Stafford RS, et al. Ambulatory treatment of type 2 diabetes in the U.S., 1997-2012. Diabetes Care 2014;37:985-92.

17. Hampp C, Borders-Hemphill V, Moeny DG, et al. Use of antidiabetic drugs in the U.S., 2003-2012. Diabetes Care 2014;37:1367-74.

18. Garber AJ, Abrahamson MJ, Barzilay Jl, et al. AACE/ACE comprehensive diabetes management algorithm 2015. Endocr Pract 2015;21:438-47.

19. Riethof M, Flavin PL, Lindvall B, et al. Diagnosis and management of type 2 diabetes mellitus in adults. Bloomington, MN: Institute for Clinical Systems Improvement, 2012.

20. Shyangdan DS, Royle P, Clar C, et al. Glucagon-like peptide analogues for type 2 diabetes mellitus. Cochrane Database Syst Rev 2011(10):CD006423.

21. Liu SC, Tu YK, Chien MN, et al. Effect of antidiabetic agents added to metformin on glycemic control, hypoglycemia and weight change in patients with type 2 diabetes: a network meta-analysis. Diabetes Obes Metab 2012;14:810-20. 
22. Niyomnaitham S, Page A, La Caze A, et al. Utilisation trends of rosiglitazone and pioglitazone in Australia before and after safety warnings. BMC Health Serv Res 2014;14:151.

23. Starner $\mathrm{Cl}$, Schafer JA, Heaton $\mathrm{AH}$, et al. Rosiglitazone and pioglitazone utilization from January 2007 through May 2008 associated with five risk-warning events. J Manag Care Pharm 2008;14:523-31.

24. Cohen A, Rabbani A, Shah N, et al. Changes in glitazone use among office-based physicians in the U.S., 2003-2009. Diabetes Care 2010;33:823-5.

25. Donnelly LA, Morris AD, Evans JM, DARTS/MEMO collaboration. Adherence to insulin and its association with glycaemic control in patients with type 2 diabetes. QJM 2007;100:345-50.

26. Cramer JA, Pugh MJ. The influence of insulin use on glycemic control: how well do adults follow prescriptions for insulin? Diabetes Care 2005;28:78-83.

27. Peyrot M, Rubin RR, Kruger DF, et al. Correlates of insulin injection omission. Diabetes Care 2010;33:240-5.

28. Peyrot M, Rubin RR, Lauritzen T, et al., International DAWN Advisory Panel. Resistance to insulin therapy among patients and providers: results of the cross-national Diabetes Attitudes, Wishes, and Needs (DAWN) study. Diabetes Care 2005:28:2673-9.

29. Larkin ME, Capasso VA, Chen CL, et al. Measuring psychological insulin resistance: barriers to insulin use. Diabetes Educ 2008;34:511-17.

30. Walz L, Pettersson B, Rosenqvist U, et al. Impact of symptomatic hypoglycemia on medication adherence, patient satisfaction with treatment, and glycemic control in patients with type 2 diabetes. Patient Prefer Adherence 2014;8:593-601.
31. Abe M, Okada K, Soma M. Antidiabetic agents in patients with chronic kidney disease and end-stage renal disease on dialysis: metabolism and clinical practice. Curr Drug Metab.

2011:12:57-69.

32. Pawaskar M, Bonafede M, Johnson B, et al. Medication utilization patterns among type 2 diabetes patients initiating Exenatide BID or insulin glargine: a retrospective database study. BMC Endocr Disord 2013;13:20.

33. Liebl A, Breitscheidel L, Nicolay C, et al. Direct costs and health related resource utilization in the 6 months after insulin initiation in German patients with type 2 diabetes mellitus in 2006: INSTIGATE study. Curr Med Res Opin 2008;24:2349-538.

34. Li Y, Xu W, Liao Z, et al. Induction of long-term glycemic control in newly diagnosed type 2 diabetic patients as associated with improvement of beta-cell function. Diabetes Care 2004;27:2597-602.

35. Ryan EA, Imes S, Wallace C. Short-term intensive insulin therapy in newly diagnosed type 2 diabetes. Diabetes Care 2004;27:1028-32.

36. Schmittdiel JA, Uratsu CS, Karter AJ, et al. Why Don't diabetes patients achieve recommended risk factor targets? Poor adherence versus lack of treatment intensification. J Gen Intern Med 2008:23:588-94.

37. Sidorenkov G, Voorham J, Haaijer-Ruskamp FM, et al. Association between performance measures and glycemic control among patients with diabetes in a community-wide primary care cohort. Med Care 2013;51:172-9.

38. Sidorenkov G, Voorham J, de Zeeuw D, et al. Do treatment quality indicators predict cardiovascular outcomes in patients with diabetes? PLOS ONE 2013;8:e78821.

39. Zafar A, Davies M, Azhar A, et al. Clinical inertial in management of T2DM. Prim Care Diabetes 2010;4:203-7. 